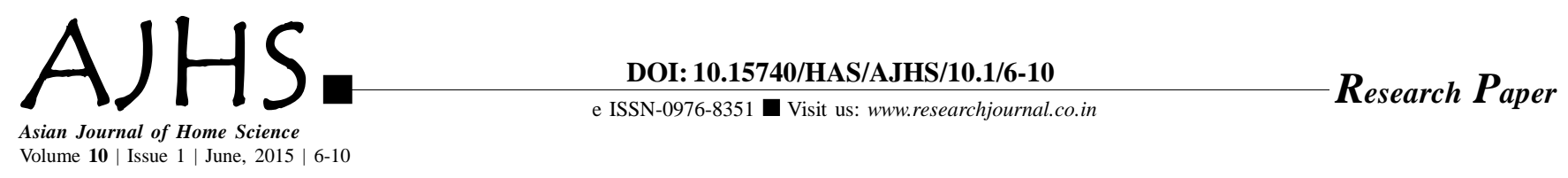

\title{
Study on changes in basal metabolic rate, body weight and fat mass per cent in hypothyroidism
}

\author{
PARUL BORA AND KALPANA KULSHRESTHA
}

Received: 17.09.2014; Revised: 02.03.2015; Accepted: 12.03.2015

See end of the paper for authors' affiliations PARUL BORA

Department of Foods and Nutrition, College of Home Science, G.B. Pant University of Agriculture and Technology, PANTNAGAR (UTTARAKHAND) INDIA

Email : parulbora@gmail.com
ABSTRACT : Thyroid is an endocrine gland located below the larynx. The principal thyroid hormones are thyroxin $\left(\mathrm{T}_{4}\right)$ and tri-iodothyroxine $\left(\mathrm{T}_{3}\right)$. The current study was carried out to investigate the changes in body weight, basal metabolic rate, total fat per cent and prevalence of obesity in hypothyroid subjects. The obesity epidemic has reached alarming numbers, the problem is multi-faceted and requires the understanding of different areas in order to effectively address the growing obese population and begin to reverse the current trends. The present study is cross-sectional in design and aimed at understanding the association between thyroid function and obesity in individuals with normal and underactive thyroid function. It was observed that fat mass per cent, body weight and BMI of hypothyroid subjects were significantly higher than the normal subjects while significant low basal metabolic rate was observed among hypothyroid subjects.

KEY WORDS: BMI, Obesity, Fat per cent, Basal metabolic rate, Underactive thyroid

- HOW TO CITE THIS PAPER : Bora, Parul and Kulshrestha, Kalpana (2015). Study on changes in basal metabolic rate, body weight and fat mass per cent in hypothyroidism. Asian J. Home Sci., 10 (1) : 6-10. 